\title{
Escolarização de alunos com deficiência e as inter-relaçōes família, escola e gestores públicos da educação especial'
}

\author{
Edson Pantaleão Alves* \\ Reginaldo Celio Sobrinho**
}

\section{Resumo}

Neste texto objetiva-se evidenciar as implicações do processo de ressignificação do conhecimento social relativo à educabilidade da pessoa com deficiência na inter-relação família, escola e gestores públicos da educação especial. Articula-se os resultados de duas pesquisas que focalizaram as políticas de Educação Especial no Estado do Espírito Santo. A primeira pesquisa abordou as relações entre as instituições especializadas e a escola comum e ancorou-se na perspectiva de pesquisa do tipo etnográfico. A segunda focalizou a formação continuada de gestores públicos de Educação Especial e assumiu os pressupostos da pesquisa-ação colaborativo-crítica. Ambas utilizaram como instrumento de coleta de dados: questionário, entrevista semiestruturada, estudo de documentos e a dinâmica de grupo focal. Na análise dos dados, adotou-se os pressupostos da Sociologia Figuracional elaborada por Norbert Elias, fundamentalmente, a noção de conhecimento e suas implicações no processo de distribuição de chances de poder nas inter-relações humanas. Os dados evidenciam que os conhecimentos relativos à inclusão social, acessados de diferentes formas pelos participantes da pesquisa, assumem sentidos e significados que possibilitam a uns e a outros questionarem situações que limitam o percurso formativo-educativo do aluno com deficiência. Conclui-se que, nas sociedades recentes, as inter-relações dos pais e dos profissionais, balizadas pela ressignificação do conhecimento social sobre a educabilidade das pessoas com deficiência, vêm produzindo outras necessidades emocionais nessas pessoas, nos seus familiares e nos profissionais do ensino, movimentando a balança de poder nas suas inter-relações.

Palavras-chave: Conhecimento; Equilíbrio de poder; Deficiência.

\footnotetext{
* Professor Doutor do Departamento de Educação, Política e Sociedade do Centro de Educação da Univer sidade Federal do Espírito Santo, Espírito Santo, Brasil.

** Professor Doutor do Departamento de Educação, Política e Sociedade do Centro de Educação da Universidade Federal do Espírito Santo, Espírito Santo, Brasil.
} 


\title{
Schooling of students with disabilities and the family, school and special education public administrators interrelationships
}

\begin{abstract}
This paper aims to evince the implications of the social knowledge reframing process related to disabled people educability in the family, school and special education public administrators. It articulates results of two researches that focused on Special Education policies of Espirito Santo. The former research approached the relations between specialized institutions and regular school and based itself on the ethnographical research perspective. The later focused on continued training of Special Education public administrators and assumed the collaborative critical action research assumptions. Both used data collection instruments such as: questionnaire, semi-structured interview, document studies and group dynamics. The data analysis embraced Norbert Elias' Figurational Sociology assumptions, fundamentally, the notion of knowledge and its implications on the distribution of power chances process in the human inter-relationships. The data indicate that social inclusion knowledge, when accessed in different ways by the research participants, assumes sense and meaning that empower questioning concerning situations that limit the educational process of student with disabilities. It was concluded that in modern societies the inter-relationships between parents and educational professionals based on social knowledge reframing about disabled people educability are engendering other emotional necessities on these people, on their relatives and on teaching professionals, changing the power balance between their inter-relations.
\end{abstract}

Keywords: Knowledge; Power balance; Disability.

\section{Introdução}

Ocupamo-nos, neste texto, em refletir sobre as implicações do processo de ressignificação do conhecimento social relativo à educabilidade da pessoa com deficiência nas inter-relações estabelecidas entre familiares de estudantes com deficiência, profissionais do ensino comum e profissionais que atuam na administração pública estadual. Os dados, aqui sistematizados, decorrem de dois estudos desenvolvidos, recentemente, no âmbito do grupo de pesquisa "Formação de profissionais, práticas pedagógicas e políticas de inclusão escolar".

Como tentativa de responder ao propósito deste texto, nossas análises tomam como referência os pressupostos da sociologia figuracional, elaborados por Norbert Elias, fundamentalmente, a noção de conhecimento e suas implicações no processo de distribuição de chances de poder nas inter-relações humanas. 
Segundo Elias (2005), o conhecimento é o processo de construção (e de consolidação) do conjunto de símbolos compartilhados pelas pessoas num grupo específico. O conhecimento é um meio de orientação para a vida em sociedade. Então, conforme Gutiérrez (2005, p. 155), em Elias, “[...] o conhecimento não é o resultado do trabalho de um 'eu' isolado que partiu do zero, mas um processo de aprendizagem de um 'nós', consolidado ao longo do tempo". Em outros termos, o conhecimento não é, de maneira alguma, uma atividade atemporal e a-histórica, é um processo de longo prazo, que tem um caráter coletivo (GUTIÉRREZ, 2005).

Nessa discussão, é importante destacar a noção elisiana de que "[...] o acesso a um conhecimento mais amplo e a maiores e mais compreensivos meios de orientação, incrementa o poder potencial dos grupos humanos [...]" (ELIAS, 1994, p. 57), ocasionando tensões e possíveis reconfigurações de "lugares" de indivíduos e grupos nas inter-relações estabelecidas. Nesse sentido, o conhecimento tem implicações no processo de distribuição de chances de poder nas inter-relações humanas.

De fato, nas sociedades recentes, a ampliação e a disseminação do conhecimento vêm atingindo, de diferentes formas e intensidade, indivíduos e grupos. No curso do século XX, o aumento do contato entre diferentes indivíduos e grupos que estavam acostumados a evitar uns aos outros atribuiu pertinência aos questionamentos referentes aos costumes naturalizados pelas gerações anteriores. Diferentes grupos de indivíduos tiveram acesso aos centros de poder estabelecidos, e isso provocou uma "[...] mistura de códigos e ideais do grupo ascendente com os dos anteriormente superiores" (WOUTERS, 2009, p. 96). Então, "[...] uma variedade cada vez maior de alternativas comportamentais e emocionais passou a ser socialmente aceitável e esperada [...]" de uns e de outros (WOUTERS, 2009, p. 96).

Assim, por exemplo, na geração atual, um número cada vez maior de pessoas vislumbra processos sociais mais inclusivos, fundamentados numa expectativa de que todos podem e devem usufruir de um conjunto de direitos sociais, entre eles, o direito à escolarização. Nos dois estudos concluídos recentemente no âmbito do nosso grupo de pesquisa, observamos que, de diferentes formas, os familiares, os profissionais do ensino comum e os profissionais que atuam na administração pública estadual teceram argumentos em torno dessa questão.

A seguir, apresentaremos, brevemente, os aspectos teórico-metodológicos que subsidiaram o processo de coleta e de sistematização de dados nas duas pesquisas empreendidas pelo grupo de pesquisa "Formação de profissionais, práticas pedagógicas e políticas de inclusão escolar". Em seguida, apresentamos e discutimos os dados como tentativa de responder ao propósito deste texto, para finalizar com algumas considerações para futuros debates.

\section{Aspectos teórico-metodológicos}

Adotando os pressupostos da sociologia figuracional, descartamos a possibilidade de utilizar "[...] métodos baseados nos pressupostos tácitos de que os fe- 
nômenos sociais seriam combinações de variáveis atômicas que servem aos cientistas naturais como um de seus principais modelos" (ELIAS; SCOTSON, 2000, p. 53). Ora, esses pressupostos se fazem presentes em um método de pesquisa que concebe a dicotomia indivíduo e sociedade, compreendendo esta última como um amontoado de pessoas e, portanto, como algo que pode ser estudado estatisticamente. Tal forma de produzir conhecimento, nas ciências sociais, indica-nos a possibilidade e a legitimidade de estudos cuja atenção é desviada das relações específicas que as pessoas estabelecem entre si.

Diferente disso, no processo de coleta e de sistematização dos dados, colocamo-nos diante da necessidade de descartar a imagem do indivíduo fechado ou solitário que existe antes e independente das relações. Assim, desde a elaboração dos instrumentos (os roteiros das entrevistas, dos grupos focais, os questionários) aos contatos com os sujeitos da pesquisa, à sistematização e às análises dos dados, buscamos considerar a teia de relações vividas pelas pessoas envolvidas em nossas pesquisas. Investimos, permanentemente, em perceber o contexto de discussão, as tensões emergentes, as propostas, o movimento dos indivíduos e/ou grupos, os "encontros/ desencontros" dos processos vividos (JESUS, 2008).

Essa atitude nos ajudou a compreender um pouco melhor aspectos da história pessoal dos sujeitos da pesquisa. Esses aspectos, mediados pela ressignificação do conhecimento social relativo à educabilidade da pessoa com deficiência, subsidiavam as decisões e as escolhas que os sujeitos faziam quando respondiam às perguntas e discutiam as questões colocadas em debate durante os contatos - as entrevistas e os grupos focais - no desenvolvimento dos dois estudos que realizamos.

No primeiro estudo, intitulado Políticas de Educação Especial no Espírito Santo: questões atravessadoras na relação instituição especializada e escola comum, objetivamos analisar a política educacional de atendimento praticado nas instituições especializadas em Educação Especial no Estado do Espírito Santo. Na realização desse estudo, optamos pela metodologia de pesquisa do tipo etnográfico. Pela via da pesquisa do tipo etnográfico, buscamos promover um contato direto com o campo de investigação, utilizando-nos de dispositivos que ampliassem nosso olhar sobre os processos e as relações que ali se instituem. Ressaltamos, ainda, que a pesquisa do tipo etnográfico apresenta natureza descritiva, centrando-se sua principal preocupação no significado que as ações e os acontecimentos possuem para as pessoas e os grupos estudados. É, nesse sentido, que André (1995, p. 29) afirma: “[...] O pesquisador deve tentar aprender e retratar essa visão pessoal do participante".

Outra característica dessa abordagem teórico-metodológica refere-se à condição de mediador assumida pelo pesquisador. De fato, na pesquisa do tipo etnográfico, "[...] os resultados [são] aplicados ou utilizados imediatamente, na solução de problemas que ocorram na realidade" (ANDER-EGG, apud MARCONI; LAKATOS, 1999, p. 22). Finalmente, há que se considerar que essa perspectiva investigativa pretende não só descrever e interpretar a realidade, mas também propor possíveis mudanças com base nas informações e nos dados que emergirem durante o estudo. 
Constituíram sujeitos dessa pesquisa: membros da equipe pedagógica das instituições especializadas (coordenador pedagógico, pedagogo, supervisor); docentes e profissionais da área clínica que atuam nas instituições especializadas; profissionais da área de gestão de recursos financeiros e/ou presidentes das instituições especializadas e familiares (pai, mãe ou responsável) das pessoas beneficiadas pelos serviços das instituições especializadas. Participaram do estudo, efetivamente, quarenta e seis instituições especializadas, sendo vinte e seis APAE's e vinte Pestalozzis, localizadas nas diferentes regiões do Estado. Como forma de organização territorial, para a coleta de dados, assumimos a divisão regional proposta pela SEDU em onze Superintendências Regionais de Educação (SRE) ${ }^{2}$ nas quais agrupamos as instituições pesquisadas.

Na dinâmica de coleta dos dados, foram utilizados como ferramenta grupos focais; questionários; visitas às instituições especializadas; entrevistas coletivas semiestruturadas, e estudo de documentos.

O segundo estudo, intitulado Políticas de Educação Especial no Espírito Santo: implicações para a formação continuada de gestores públicos de Educação Especial focalizou a formação e a constituição dos gestores públicos de Educação Especial, buscando potencializar o diálogo teórico-prático. No cumprimento desse objetivo, tomamos teórico-metodologicamente, o referencial da pesquisa-ação colaborativo-crítica. Nessa abordagem teórico-metodológica, busca-se a aproximação entre sujeito e pesquisador, assumindo a colaboração como essencial ao processo de intervenção para descobrir sentidos da realidade. A ênfase está no processo de autorreflexão coletiva na busca pela superação das tensões vividas, muito delas distorcidas pela lógica positivista que ainda predomina nas práticas educativas. Nessa perspectiva, pesquisadores acadêmicos e pesquisadores dos sistemas e das escolas devem buscar a transformação das práticas educativas e sociais.

Participaram dessa pesquisa-ação: gestores da Educação Especial da rede pública municipal e estadual do Estado do Espírito Santo, dos quais 33 (trinta e três) pertencentes às 11 (onze) Superintendências Regionais de Educação do Estado do Espírito Santo (SRE); 71 (setenta e um) às Secretarias Municipais de Educação e 3 (três) técnicos da Secretaria de Estado da Educação (SEDU central), totalizando 107 (cento e sete) profissionais.

Na concepção teórico-metodológica adotada, nesse segundo estudo, buscou-se um processo de negociação com os atores do contexto educativo - os gestores/ técnicos da rede pública da Educação Especial do Estado do Espírito Santo - a fim de diagnosticar as demandas existentes e construir estratégias de ação para a mudança.

No processo de coleta de dados, os sujeitos foram subdivididos por regiões administrativas, jurisdicionadas às 11 (onze) Superintendências Regionais de Educação. No primeiro momento, realizamos encontros utilizando a estratégia dos grupos focais (GATTI, 2005), os quais propiciaram um movimento de engajamento dos participantes, com o propósito de constituição do currículo do curso de formação conti- 
nuada. Na ocasião, indagou-se sobre o que deveria se constituir como conhecimento profissional dos gestores da Educação Especial.

O segundo momento da pesquisa se deu por meio de um processo de formação continuada a partir de um curso de aperfeiçoamento semipresencial, intitulado Curso de Gestores Públicos em Educação Especial na Perspectiva da Inclusão Escolar. O curso teve como objetivo central formar profissionais gestores que pudessem se tornar impulsionadores das questões da gestão da Educação Especial, considerando-os como mediadores em sua região de abrangência e tendo como premissa teórico-metodológica a formação-ação. No geral, o curso teve a duração de 200 horas, sendo 102 horas presenciais e 98 horas de atividades não presenciais, no período de maio a novembro de 2011.

Durante os meses de abril e maio de 2012, retornamos às SRE's para discutir com os gestores o processo de materialização de planos e de projetos de intervenção, elaborados durante o curso, bem como o desenvolvimento das ações políticas em seus municípios e superintendências. Nesse terceiro momento, utilizamos, novamente, a estratégia do grupo focal. Tivemos por objetivo analisar, com os profissionais, as mudanças ocorridas no contexto de trabalho, as possibilidades, as tensões e realizações a partir do curso.

No momento de acompanhamento, procuramos dialogar sobre os movimentos instituintes disparados pelos profissionais, para a constituição de novas e outras práticas educacionais e de gestão, que considerem a presença do aluno com indicativos para a Educação Especial no ensino comum. Refletimos, ainda, sobre as possibilidades e as tensões na implementação de políticas públicas que garantam, com qualidade, o processo de escolarização dos alunos sujeitos da Educação Especial.

\section{Resultados e discussão}

A ampliação do conhecimento relativo à educabilidade das pessoas com deficiência, no decorrer do século passado, tem contribuído para uma maior compreensão sobre o processo educativo dessas pessoas nos anos recentes, principalmente, quando consideramos a vida em sociedades complexas como as nossas.

Iniciamos, todavia, um novo século com bastante dificuldade em consolidar e disseminar saberes mais evidentes que nos ajudem a reconhecer o direito que as pessoas com deficiência têm de ser compreendidas na sua condição específica, de viver um modo de vida que, em muitos sentidos, é diferente do modo de vida dos outros.

Tomando, porém, a noção elisiana de que "[...] as interdependências mudam, à medida que as sociedades se tornam cada vez mais diferenciadas e estratificadas" (ELIAS, 2005, p. 147), é possível dizer que outros saberes relativos aos processos formativo-educativos das pessoas com deficiência vêm fundamentando as figurações sociais formadas por familiares, por profissionais do ensino comum e da administração pública. 
Diferentemente do que ocorria em outros momentos, quando as instituições especializadas assumiram protagonismo no processo educativo das pessoas com deficiência, as vozes dos sujeitos envolvidos em nossos estudos traduzem expectativas positivas quanto à inserção dessas pessoas no contexto do ensino comum, ainda que permaneçam anunciando a preferência pelo trabalho desenvolvido na instituição especializada, sobretudo do ponto de vista dos pais.

Parece oportuno registrar as preocupações dos pais, dos gestores públicos e dos profissionais do ensino comum a esse respeito, pois, para os pais, os filhos só seriam mais bem atendidos no ensino comum se, na escola, pudessem contar com profissionais que tivessem preparação para lidar com as demandas desses alunos. Durante a entrevista coletiva na SRE 3, uma participante destacou:

[...] volta e meia eu estava na escola, conversava com o professor. [...] Eles achavam que ela era preguiçosa, que não queria fazer. Aí ela chegava em casa, ela chorava, aí eu conversava com os professores, e olha que ela é bem diferente da maioria, porque ela interage, ela conversa, lê, escreve. Então o que eu vejo é que tem que ter um lugar com professores que tenham tempo e condições para cuidar deles. [...] (Mãe - SRE 3)

Nessa mesma direção, na entrevista realizada em Barra de São Francisco, outro participante declarou: "[...] Na escola comum os professores são esforçados, correm atrás, mas não têm estudo para trabalhar com essas crianças [...]" (Pai - SRE 11).

Avaliando o desempenho de seu filho no ensino comum, na SRE 7 uma participante declarou:

O que eu vejo o meu filho fazer na escola comum é desenhar! É homem aranha, é Ben 10 [...] eu trago para vocês vê o caderno, só desenho. É desenhar e pintar, desenhar e pintar. Quer dizer, não dão uma atividade [...] A única coisa que ele aprendeu na escola pública até hoje foi isso, desenho. (Mãe - SRE 7)

Outra mãe, participante da entrevista, observou:

[...] Ele não aprendeu nada na escola, nessa primeira escola. Ele tem 14 anos e está na sexta série. Não sabe ler, nem escrever. Sabe aonde que ele aprendeu a escrever o nome dele e está aprendendo a escrever meu nome e tudo? É aqui na APAE. [...] (Mãe-SRE 3)

Também, ressentindo a falta de preparação dos professores, a falta de estrutura e de recursos na escola comum, participante da entrevista coletiva na SRE 11 fez a seguinte declaração:

[...] eu estive com minha filha aqui quando fundou a Pestalozzi. Aí eu fui embora. Fui morar em outro estado e quando voltei para cá, eu matriculei ela aqui. Com o trabalho deles (da Pesta- 
lozzi), ela melhorou bastante. [...] Minha filha vai para a escola, mais pela inclusão, porque ela não tem capacidade de aprendizado [...]. (Mãe - SRE 11)

Nessas declarações, a instituição especializada emerge como espaço favorável ao atendimento das demandas das pessoas com deficiência. A instituição especializada ganha a preferência de pais e de profissionais do ensino, sempre que, na compreensão desses sujeitos, o desenvolvimento humano e/ou a apropriação de símbolos sociais significativos estiverem ancorados numa perspectiva médico-clínica de caráter biologizante. Aqui, o indivíduo que apresenta determinada especificidade (deficiência) é atendido na sua particularidade, sem menção ao aspecto social, inerente aos processos formativo-educativos.

Os profissionais que atuam na administração pública também se ressentem do despreparo por parte dos professores, dos pedagogos e dos diretores para receber os alunos com deficiência na escola comum. Quando solicitados a apontar os desafios e as tensões relativos à escolarização das pessoas em situação de deficiência, destacaram:

[...] a insegurança dos diretores e pedagogos em decidir o encaminhamento, a falta de conhecimento; [...] a falta de entrosamento dos profissionais; [...] precisamos compreender como avaliar esses alunos, adaptando-os ao sistema de avaliação que temos; [...] falta uma equipe multidisciplinar; falta qualificação de profissionais [...] falta construir maneiras de oferecer uma educação de qualidade. Finalmente, queixavam-se: [...] os cursos de formação continuada não atendem as questões práticas no atendimento com os alunos com deficiência. (Síntese do conjunto de questões apresentadas pelos profissionais que atuavam na SRE 7, durante o grupo focal)

Os professores do ensino comum reclamavam a organização de espaços sistemáticos de formação continuada no cotidiano escolar. A esse respeito, uma das professoras destacou: "[...] outra questão que a gente tem percebido e que é crucial para a educação é a formação. Levar a formação para os profissionais da escola. Quando a gente tem o conhecimento, dá uma abertura muito maior" (Professora do ensino comum, grupo focal na SRE 7).

$\mathrm{Na}$ compreensão dos participantes da pesquisa, a escola comum também padece com a falta de estrutura física e de recursos mais adequados às demandas das pessoas com deficiência: "[...] Só tem uma escola aqui, e ela não tem estrutura para receber esses alunos. Espaço, adaptação física, não tem banheiros adaptados, não tem espaço suficiente" (Mãe - SRE ll).

Os profissionais que atuam na administração pública admitem essa lacuna: "[...] Falta de espaços e salas nas escolas regulares para o atendimento aos alunos acima dos 14 anos". Mais especificamente, observaram a necessidade de maior compreensão acerca de uma importante questão: "[...] Financiamento para a Educação 
Especial enquanto modalidade de ensino [...]". Indagam eles: "Qual é o papel e a responsabilidade financeira dos municípios e do estado nas ações que buscam a garantia da inclusão dos alunos com deficiência nas escolas comuns?" (Síntese do conjunto de questões apresentadas pelos participantes do grupo focal realizado na SRE 11).

Os profissionais do ensino comum e da administração pública apontam também outra lacuna: "[...] Falta de articulação entre os outros setores, dentro da secretaria de educação, refletindo numa ação desarticulada e isolada na secretaria" (Síntese do conjunto de questões apresentadas pelos participantes do grupo focal realizado na SRE 8).

Do que buscamos discutir neste texto, parece oportuno considerar que a entrada das pessoas com deficiência no espaço escolar evidencia dilemas e desafios vividos historicamente no ensino comum, fato que produz a necessidade da ressignificação do conhecimento social relativo à educabilidade dessas pessoas. Vale destacar que grande parte das melhorias solicitadas para o processo de formação de pessoas com deficiência no ensino comum tem sido alvo de discussão e de solicitação de melhorias para os demais alunos no curso dos últimos anos, principalmente, durante o século XX.

É interessante considerar que os argumentos dos profissionais do ensino e da administração pública se organizam em torno, exatamente, das lacunas deixadas no processo de concretização de uma escola de qualidade social para todos. Mas, no fundo, ao longo dos últimos anos, os discursos da impossibilidade se deslocam, e, paulatinamente, ganham centralidade as questões relativas ao "como" e ao "o que" fazer, já que o aluno com deficiência não conseguiria se beneficiar de uma escola que ainda contribui restritamente no processo de formação de tantos outros indivíduos que por ela passam.

Nos dados que sistematizamos, pudemos observar que os conhecimentos sociais relativos à inclusão social, acessados de diferentes formas pelos participantes da pesquisa, assumem sentidos e significados que potencializam expectativas de superar determinadas posturas e práticas pedagógicas desenvolvidas pelos professores do ensino comum junto às pessoas com deficiência.

Nessa direção, alguns pais demonstram satisfação com as medidas tomadas na escola: "[...] agora tem a diretora e ela colocou alguém só para o meu menino e ele começou a interagir mais com os outros alunos. Ele tem 7 anos. Ele desenvolveu muito a fala" (Mãe, Pestalozzi 7).

Outra participante declarou: "[...] precisa perguntar aos pais como seus filhos são. Capacitar o professor. Fazer um estudo dos alunos. Começar de 6 a 7 anos, pois com mais idade não adianta ir para a escola" (Mãe, Pestalozzi 7). 
Para os profissionais que atuam na administração pública, a inclusão escolar dos alunos com deficiência se dará à medida que houver " [...] maior articulação do professor especializado com o resto da escola (SRE 9, SRE 10, SRE 5). Outros aspectos facilitadores dos processos inclusivos escolares seriam o "[...] acesso e o conhecimento de documentos norteadores da educação na perspectiva da inclusão escolar [...]" (SRE 4, SRE 11)". Os profissionais também destacam a falta de adaptação aos conteúdos curriculares, e consideram a necessidade de "[...] maior empenho em trazer os pais para dentro da escola". Finalmente, admitem a "[...] falta de diálogo entre as secretarias" (SRE 10, SRE 11).

safio

Os profissionais que atuam na administração pública assumem como de-

[...] o diálogo dessa equipe de gestão com as unidades escolares, com o ensino comum e outras equipes de gestão de secretaria de educação. Como fazer a ligação entre os gestores do ensino fundamental e de educação infantil para que todos falem uma mesma linguagem? Que exista um alinhamento das ações. (SRE 4, SRE 10, SRE 11)

Os profissionais do ensino e da administração pública consideram importante a realização de estudos sobre

financiamento, legislação; acessibilidade (física, curricular, comunicação alternativa); [...] currículo para os alunos com TGD e altas habilidades/superdotação; [...] avaliação escolar dos alunos com deficiência: como, quando, e que registros? (SRE 10, SRE 8, SRE 3)

Admitir que, em inter-relações, os indivíduos constroem símbolos e esses constroem os indivíduos e moldam as relações que eles estabelecem, pode nos ajudar a compreender melhor a crença alimentada pelos pais de que seus filhos precisam de alguém que possa cuidar somente deles no contexto escolar, ou a expectativa de que, se os filhos não tiverem acesso à escola desde cedo, com mais idade já não adianta mais. Vale considerar que esses sentimentos foram nutridos ao longo das últimas gerações, a partir dos conhecimentos sobre deficiência sistematizados pelas áreas médica e psicológica.

Em grande parte dos casos, esses estudos estiveram pautados ora numa abordagem que compreende o indivíduo como o produto das estruturas sociais, ora numa perspectiva que compreende a deficiência a partir de si mesma ou a partir do próprio indivíduo que a porta, um homo clausus, que existe antes e independentemente das inter-relações. Numa ou noutra compreensão, esses estudos terminavam por ignorar o fato de que as representações de si, a diferença e o outro são construções histórico-sociais, que emergem nas figurações humanas.

Essas explicações, todavia, passaram a ser questionadas com mais evidência nos últimos anos, sobretudo, em decorrência da ampliação das cadeias de inter- 
dependências articuladas à crescente ressignificação do conhecimento sobre essa questão. De fato, conforme Wouters (2009), no curso do século XX, grupos inteiros ascenderam socialmente, emancipando-se, tornando menos hierárquicas quase todas as relações. Para o autor, particularmente nas cidades em expansão,

[...] pessoas antes acostumadas a evitar umas às outras eram agora forçadas a tentar manter ou encobrir a distancia social sob condições de proximidade, ou acomodar-se e acostumarse à mistura social. [...] na outra direção vinham os ataques às formas de manter a distância como expressão de superioridade. Na medida em que algum grau de mistura social tornou-se inevitável, as formas mais extremas de distância e demonstração de superioridade foram banidas [...]. (WOUTERS, 2009, p. 109)

Vinculada a essa questão, conforme vimos destacando, a sistematização de um conhecimento mais amplo relativo à deficiência e aos aspectos do desenvolvimento de pessoas nessa condição contribuiu para o redimensionamento do poder potencial daqueles sujeitos envolvidos nesse processo, por exemplo, os pais e os profissionais do ensino.

No curso histórico, observamos que, como resultado das tensões vividas em contextos sociais que objetivam garantir o acesso de todos aos bens sociais, os profissionais do ensino comum e da administração pública destacam questões relativas à pertinência da articulação entre o trabalho desenvolvido pelo professor especialista e o professor do ensino comum, à necessidade de promover adaptação dos conteúdos escolares, à importância de uma maior aproximação com os pais dos alunos em situação de deficiência e, de maneira intensa, à necessidade de acessar documentos norteadores da inclusão escolar. $\mathrm{O}$ atendimento a essas questões emerge como dispositivo capaz de garantir melhor qualidade no trabalho da escola perante os processos inclusivos.

Por um lado, as queixas e indicações dos participantes das pesquisas expressam o permanente movimento de ressignificação do conhecimento e, por outro lado, evidenciam que as novas bases para a orientação e para a comunicação dos (e entre os) indivíduos pertencentes às gerações atuais garantem certa reconfiguração de lugares nas inter-relações de pais, profissionais do ensino e da administração pública. Numa e noutra direção, fica patente a seguinte ideia: “[...] Há somente uma maneira pela qual os seres humanos podem crescer e sobreviver: estando em grupo" (GOUDSBLOM, 2009, p. 55). Definitivamente, o homem não é um ser fechado e solitário que se desenvolve independentemente das relações que estabelece com os outros.

\section{Considerações finais}

Em vista do conjunto de dados que sistematizamos, reiteramos que tensões específicas e muito diferenciadas são vividas na teia das relações que os pais estabelecem com os profissionais que lidam com seus filhos. Em muitas situações, a história produzida nessas relações termina por legitimar as baixas expectativas quanto à educabilidade das pessoas com deficiência, inclusive quando matriculadas no ensino comum. 
Na nossa compreensão, as baixas expectativas quanto à educabilidade de pessoas com deficiência constituem o obstáculo mais significativo quando pretendemos que, de fato, os pais e os profissionais apostem no trabalho educativo desenvolvido pela escola comum. Esse obstáculo se apresenta robusto; afinal, o laudo médico e a sobreposição do trabalho clínico em relação ao pedagógico ainda aparecem com ímpeto nas políticas educacionais estabelecidas e praticadas nos anos recentes.

De toda forma, os dados também nos permitem observar que, concomitante a essa perspectiva médico-clínica, a ampliação das cadeias de interdependências, associada à crescente ressignificação do conhecimento social relativo à educabilidade das pessoas com deficiência, vem produzindo outros referentes de poder nas figurações sociais formadas por familiares, profissionais do ensino e da administração pública, possibilitando a uns e a outros questionarem situações reconhecidas como excludentes e construírem mecanismos para a superação dessas situações.

Em alguns casos, os familiares e os profissionais do ensino defendem a precedência da instituição especializada em educação especial em relação à escola comum. Por um lado, justificam tal posicionamento destacando a falta de preparo dos profissionais do ensino comum, a discriminação e o preconceito vividos no contexto de escolarização e a falta de estrutura física e de recursos mais adequados às demandas das pessoas em situação de deficiência no contexto escolar. Por outro lado, enunciam, cada vez mais, a necessidade de produção de conhecimentos sobre a pessoa com deficiência, visando à garantia do direito à escolarização.

A esse respeito, vale reiterar que o conhecimento é uma ferramenta fundamental para orientação da história humana. Diferentes campos do conhecimento produzem diferentes saberes que, necessariamente, se referem a uma construção histórica realizada por sujeitos coletivos (GOHN, 2006). Pode-se, assim, compreender o campo científico como aquele que se dedica a gerar aprendizagens e saberes sobre a realidade humana.

As duas pesquisas empreendidas se apresentam, pois, como elementos capazes de potencializar a ampliação do conhecimento relativo à inclusão escolar das pessoas com deficiência. É, nesse sentido, que consideramos a pertinência de os resultados dessas pesquisas serem apropriados e significados pelos diferentes sujeitos envolvidos no processo educativo escolar - pais, professores do ensino comum, professores especialistas, diretores, equipe técnica e de gestão escolar e, profissionais que atuam na administração pública. Essa ação pode colocar em movimento a balança de poder nas figurações sociais formadas por indivíduos ou grupos diretamente envolvidos nesse processo, propiciando/provocando tensões que, de alguma forma, superem ou minimizem os mecanismos que limitam o percurso formativo-educativo do aluno com deficiência na escola comum. 


\section{Referências}

ANDRÉ, M. E. D. A. Etnografia da prática escolar. Campinas: Papirus, 1995.

ELIAS, N. Conocimiento y poder. Madrid: Las ediciones de la Piqueta, 1994

Introdução à sociologia. Lisboa: Edições 70, 2005.

ELIAS, N.; SCOTSON, J. L. Os estabelecidos e os outsiders: sociologia das relações de poder a partir de uma pequena comunidade. Trad. Vera Ribeiro, Rio de Janeiro: Jorge Zahar Editor, 2000.

GATTI, B. A. Grupo focal na pesquisa em ciências sociais e humanas. Brasília: Líber Livro Editora, 2005.

GOHN, M. G. M. A pesquisa na produção do conhecimento. Eccos revista científica, São Paulo, v. 7, n. 2, p. $253-274,2006$

GOUDSBLOM, J. A vergonha: uma dor social. In: GEBARA, Ademir; WOUTERS, Cas. (Orgs.). O controle das emoções. João Pessoa: Editora Universitária da UFPB, 2009. p. 47-60.

GUTIÉRREZ, A. V. Norbert Elías y la teoría del símbolo. Revista Sociedad y Economia, Cali/Colombia, n. 7, p. 135-157, oct. 2005. Disponível em: 〈http://dintev.univalle.edu.co/revistasunivalle/index.php/SyE.〉. Acesso em: 30/maio/2012.

JESUS, D. M. O que nos impulsiona a pensar a pesquisa-ação colaborativo-crítica como possibilidade de instituição de práticas educacionais mais inclusivas?. In: BAPTISTA, Claudio Roberto; CAIADO, Katia Regina Moreno; JESUS, Denise Meyrelles de. (Orgs.). Educação Especial: diálogo e pluralidade. Porto Alegre: Mediação, 2008. p. 139-160.

MARCONI, M. A.; LAKATOS, E. M. Técnicas de pesquisa. 4. ed. São Paulo: Atlas, 1999.

WOUTERS, C. Mudanças nos regimes de costumes e emoções: da disciplinarização à informalização. In: GEBARA, Ademir; WOUTERS, Cas. (Orgs.). O controle das emoções. João Pessoa: Editora Universitária da UFPB, 2009. p. 91-117.

\section{Notas}

1 Texto produzido a partir dos resultados de duas pesquisas: "Políticas de Educação Especial no Espírito Santo: questões atravessadoras na relação instituição especializada e escola comum" e "Políticas de Educação Especial no Espírito Santo: implicações para a formação continuada de gestores públicos de Educação Especial". Pesquisas realizadas no período de 2010 a 2012, financiadas pela Secretaria de Educação do Estado do Espírito Santo (SEDU).

2 No Estado do Espírito Santo, a Secretaria Estadual de Educação (SEDU) agrupa os municípios em onze regiões administrativas, jurisdicionadas às Superintendências Regionais de Educação (SRE).

\section{Correspondência}

Edson Pantaleão Alves - Universidade Federal do Espírito Santo, Centro de Educação, Av. Fernando Ferrari, 514, Goiabeiras, CEP: 29075910, Vitória, Espírito Santo, Brasil.

E-mail: edpantaleao@hotmail.com - rsobrinho2009@hotmail.com

Recebido em 07 de abril de 2013

Aprovado em 03 de maio de 2013

Revista Educação Especial | v. 27 | n. 48 | p. 171-184 | jan./abr. 2014

Santa Maria 
